Estudios sobre armas antiguas, arte militar y vida cultural en oriente y occidente XXX III (2013), pp. 39-56

ISSN : 0436-029X

doi: $10.3989 /$ gladius.2013.0002

\title{
ESTELAS IBÉRICAS CON LANZAS Y TROPAS AUXILIARES EN EL NORDESTE PENINSULAR
}

\author{
IBERIAN STELAE WITH IMAGES OF SPEARHEADS AND AUXILIA \\ IN NORTHEASTERN IBERIA
}

POR

Roger Riera VARgas*

\section{RESUMEN - ABSTRACT}

El hallazgo de varias estelas ibéricas en el nordeste peninsular con unos motivos decorativos muy similares entre ellas, sugiere un estudio de conjunto. Dicha decoración se caracteriza especialmente por la presencia de lanzas verticales dispuestas paralelamente en una o varias franjas horizontales, y poseen evidentes signos de relación con el grupo de estelas del Bajo Aragón. Tradicionalmente se ha asociado estos monumentos con el mundo funerario de carácter guerrero. Sin embargo, en base a su disposición, cronología y yacimientos asociados, se propone una vinculación con el movimiento de tropas auxiliares hispanas hacia el sur de la Galia entre finales del s. II e inicios del s. I a.n.e.

The discovery, on the NE of the Iberian Peninsula, of several Late Iron Age Iberian stelae, sharing very similar decorations among each other, claims for a more detailed study. This paper clearly wants to undertake so. As to the motifs, groups of vertical lances sculped on the stone at one or several horizontal levels have been traced, perhaps linked with another group of stelae generally located in Lower Aragón (North Central Spain). Traditionally, such stelae have been related to the funerary warrior cult. However, according to their location, chronology and associated settlements, I think they might function as landmarks for the Iberian auxiliary troops moving to Southern Gaul between the end of Second and the early First centuries BC.

\section{Palabras Clave - Keywords}

Estelas ibéricas; Nordeste peninsular; Auxiliares hispanos; Logística romana.

Iron age stelae; NE Iberian peninsula; Hispanii auxilia; Roman logistics.

\section{INTRODUCCIÓN A LA PROBLEMÁTICA ${ }^{1}$}

La investigación sobre las estelas de época ibérica en Cataluña ha progresado pareja al número de ejemplares localizados en esta zona, es decir, lenta pero continuamente. La escasez de piezas recuperadas al norte del Ebro, especialmente en comparación con otras áreas, como el Bajo Aragón o el Levante peninsular, quizá explica, en parte, la poca atención que han merecido en la divulgación científica. Existe, además, una gran variedad iconográfica entre ellas,

* Universitat Autònoma de Barcelona, Departament de Ciències de l’Antiguitat i de l’Edat Mitjana. Investigación realizada dentro del marco del proyecto HAR2010-19185 "La gestión política de las crisis humanitarias en el mundo grecorromano (ss. IV-I a.C.)”, roger.riera@uab.cat. 
circunstancia que dificulta poder establecer algún tipo de relación entre ellas. Por otro lado, al igual que la mayoría de estelas ibéricas localizadas en la península, las piezas recuperadas en Cataluña carecen de contexto arqueológico original; aunque la mayor parte proviene de hallazgos casuales o extracciones decimonónicas sin metodología arqueológica alguna, otras fueron halladas en el decurso de intervenciones modernas, pero reutilizadas en estructuras que nada tienen en común con su contexto original ${ }^{1}$. Así pues, uno de los problemas fundamentales a los que se enfrenta el estudio de estas piezas, es la carencia de elementos arqueológicos asociados que nos permitan fecharlas con seguridad, pese a que, como veremos, comúnmente se han asignado a los siglos II y I a.n.e. ${ }^{2}$

En este artículo se pretende profundizar sobre un tipo concreto de estela en Cataluña. Se trata de aquellos ejemplares que presentan una decoración, ya sea en esgrafiado o en bajorrelieve, con una iconografía muy similar a las del grupo de estelas del Bajo Aragón, entre las cuales destacan especialmente las representaciones de lanzas verticales. Hasta el momento se han recuperado seis estelas de este tipo en Cataluña. Otras ocho piezas, divididas en dos categorías, completan el corpus de de estos monumentos en la zona. Uno de ellos es el denominado grupo de estelas epigráficas sin decoración, que presenta similitudes con piezas del Levante peninsular (Oliver Foix, 1994) y del cual contamos con 4 seguras y una quinta de difícil adscripción ${ }^{3}$. El otro se caracteriza por su decoración de carácter astral, muy especialmente discos solares y lunas crecientes, y cuenta con 4 estelas. Existe una posible estela más, procedente de Ampurias, de la cual tan solo se conserva un fragmento. Ni siquiera estamos seguros si realmente pertenece a un monumento de este tipo, pero en cualquier caso, su cronología (fechada en el siglo VI) y su forma y decoración, parecen estar más acorde con el mundo colonial griego que con el ibérico indígena, circunstancia que la aleja de nuestro ámbito de estudio (Sanmartí Grego, 1988: 114). Por último, pero sin duda no menos importante, cabe añadir que algunas de las piezas de los tres grupos, comparten más de un estilo decorativo. Así, en una de las estelas de Badalona se puede observar decoración en bajorrelieve consistente en un conjunto de lanzas verticales vinculable al grupo del Bajo Aragón y, a la vez, un disco solar, una luna creciente y una esvástica (Carreras Candi, 1937). La composición del conjunto nos advierte que la estela fue decorada en un mismo momento y, por tanto, este tipo de muestras pone en relación dos tradiciones iconográficas distintas y complica un poco más la labor interpretativa de la investigación moderna.

La existencia de ejemplares con tan distinta decoración al norte del Ebro, sugiere un estudio específico para cada uno de los tres subgrupos antes de realizar cualquier estudio de carácter general. El propósito que perseguimos en este artículo es centrarnos en el grupo de estelas con decoración de tipo bajoaragonés, las cuales, pese a su distribución espacial bastante amplia, poseen evidentes signos de vinculación entre ellas (Quesada Sanz, 2000: 101). De ahora en adelante nos referiremos a estas piezas como al grupo de 4+2, puesto que, como veremos, existen 4 ejemplares que presentan únicamente decoración de tipo marcial mientras que otras 2 (ambas procedentes de Badalona) combinan esta iconografía con otros motivos. Esta circunstancia será debidamente analizada en su momento. Además, cabe señalar que el área de dispersión de estos ejemplares no se circunscribe en los límites de un solo pueblo ibérico del nordeste peninsular, aspecto del que difieren respecto a los ejemplares turolenses (Burillo Mozota, 2002). Según los criterios de delimitación territorial más comúnmente aceptados, nuestros ejemplares se ubican en dominios layetanos, ausetanos e indiketes (figura 1).

1 Es el caso de dos de los tres ejemplares recuperados en Badalona, que se encontraron en el transcurso de las excavaciones de la ciudad romana de Baetulo, utilizadas como losas para tapar una de las cloacas de la ciudad.

2 En adelante, todas las fechas se refieren a a.n.e., a no ser que se indique lo contrario.

3 La estela de Sant Hipòlit de Voltregà (Barcelona), presenta cuatro líneas de caracteres ibéricos junto con un disco en la parte central de la pieza. Sin embargo, se desconoce si ambos elementos son contemporáneos y, por tanto, si el disco formaba parte del monumento funerario o fue esculpido con posterioridad (VILAPLANA, 1953: 101-103). 


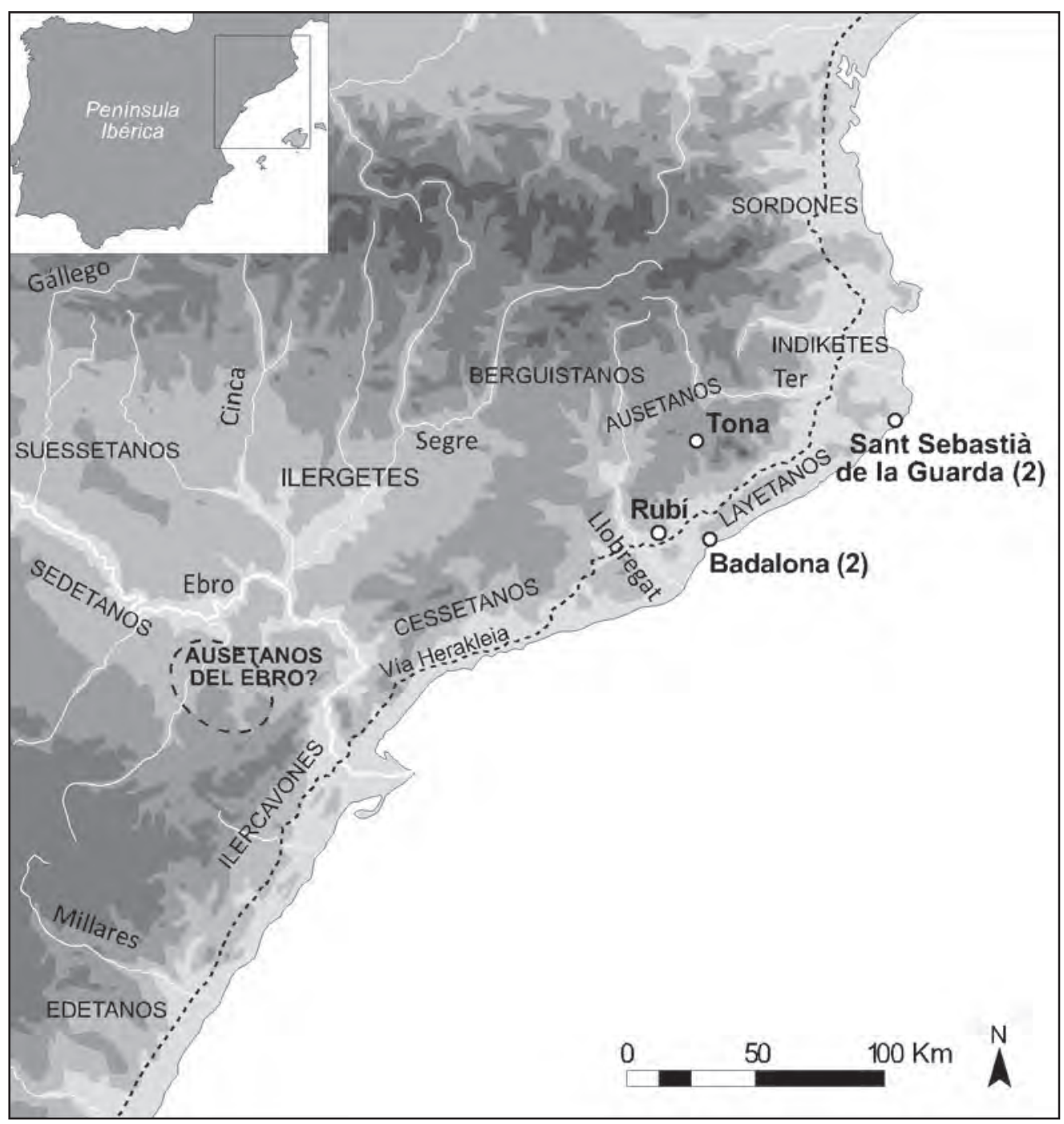

Figura 1. Localización de las estelas con decoración de tipo bajoaragonés halladas en el nordeste peninsular.

\section{HISTORIA DE LA PROBLEMÁTICA}

Las investigaciones referentes a las estelas procedentes del Bajo Aragón cuentan con una larga tradición historiográfica (Cabré, 1923; Bosch Gimpera, 1923; Fernández Fuster, 1951; Marco Simón, 1976) y bibliografía relativamente reciente (Izquierdo Peraile, 2000; Burillo Mozota, 2002; Melguizo Aísa, 2005; Marco Simón y Royo Guillén, 2012); se trata de un fenómeno muy característico de esa zona en particular y se ha puesto en relación con los denominados «ausetanos del Ebro» u ositanos (Burillo Mozota, 2002: 180). Quizá la mayor heterogeneidad de las piezas halladas en Cataluña, así como su menor número, pueda explicar la falta de un estudio de conjunto de las estelas catalanas. En efecto, algunas de ellas cuentan a lo sumo con un artículo dedicado a su análisis e interpretación, frecuentemente escrito hace ya varias décadas y que en su mayoría, no ha sido objeto de revisión. Hay que reconocer la importancia 
y el aporte que significaron en su momento estos estudios, pero lo cierto es que nuevos hallazgos pueden alterar la interpretación y la comprensión del conjunto. Además, el desarrollo de la investigación histórica exige de renovación y evolución constante, actividad que ha sido mal atendida en este campo, pese a una notable excepción (Garcés y Cebrià, 2003).

Dado que, como ya hizo F. Quesada hace una década, centraremos nuestra atención en el grupo de estelas catalanas con decoración vinculable al grupo aragonés, remitiremos de forma continua a los estudios realizados sobre ese territorio. En este sentido, los primeros análisis científicos modernos de las estelas ibéricas proceden del arqueólogo Juan Cabré (Cabré, 1923), que dedicó buena parte de su obra sobre la protohistoria aragonesa a este preciso fenómeno. Anteriormente, contamos con una breve pero reveladora noticia aportada por Adolf Schulten (Schulten, 1912) en la cual relacionaba las lanzas que aparecían en muchas de las piezas con un pasaje de Aristóteles (Pol. VII, 2, 11; 1324b). El hispanista alemán sugería que la práctica descrita por el filósofo griego de clavar las lanzas alrededor de la tumba del héroe caído habría evolucionado siglos después hasta un nivel simbólico, petrificándose en la decoración de grandes bloques de piedra.

Esta teoría tuvo buena aceptación y ha sido desarrollada en varias ocasiones (Cabré, 1923; Marco Simón, 1976; Quesada Sanz, 1994). Lo cierto es que parece una evolución lógica de esta práctica, dado que si aquello que se perseguía era glorificar al difunto y perpetuar su memoria, no había mejor manera de hacerlo que plasmarlo en un material tan perenne como la piedra $^{4}$. Cabré propuso una cronología que comprendía los siglos III-II amparándose en criterios fundamentalmente iconográficos. En este sentido, se concentró en la tipología de los escudos que llevan los jinetes de algunas de las estelas. Se trata de los escudos ovales, una tipología que en ese momento se creía propia del siglo III pero que estudios posteriores han ampliado su utilización hasta el siglo I (Quesada Sanz, 2002: 52-54). En cuanto a su naturaleza, tanto Cabré como posteriormente otros autores, vincularon las estelas al mundo funerario. Ciertamente la erección de estelas como monumentos de carácter fúnebre fue un fenómeno muy extendido en el mundo antiguo, y no solamente en la cuenca Mediterránea, aunque la falta de contexto arqueológico, tanto en Cataluña como en Aragón, nos impide afirmar que se trate indiscutiblemente de estelas de este tipo. Tal y como señaló en su día J. R. López de los Mozos (López De los Mozos, 2002), existe una gran variedad de funciones atribuibles a estas grandes losas de piedra, especialmente en aquellas que carecen de epigrafía -como es el caso- y cuyo significado es, por tanto, más difícil de descifrar. En este sentido, debemos señalar que P. Bosch Gimpera ya expresó sus dudas al respecto; el eminente arqueólogo catalán arguyó que algunas de las estelas, como la de Palermo (Caspe), se encontraron en el interior del poblado, hecho que pondría en duda el significado de esas piezas (Bosch Gimpera, 1923: 655).

Años más tarde, L. Fernández Fuster retomó el hilo de las investigaciones (Fernández Fuster, 1951) y elaboró una pequeña ficha para cada uno de los ejemplares descubiertos hasta entonces. Entre todos ellos creyó ver dos etapas evolutivas, sin precisar cronología, pero siempre entre los siglos II y I. Fernández Fuster no compartía la opinión de sus predecesores en cuanto a la interpretación de las lanzas, ni en el sentido aristotélico de representación de enemigos vencidos, ni en relación con la categoría o división militar a la que perteneció el difunto (Fernández Fuster, 1951: 72). Argumentó al respecto que, por un lado, «la organización militar, aun dentro del individualismo ibérico, se sujetaba a reglas de clan y de tribu» y no, por tanto, a centurias o cohortes. Por el otro, la interpretación aristotélica quedaba invalidada,

4 En este sentido, han sido halladas varias tumbas ibéricas con evidencias de deposiciones de lanzas hincadas en el suelo como parte de su ajuar (QUESADA SANZ, 1994: 365). 
según este autor, por la existencia de un ara romana en Solsona (Barcelona) en la cual había también lanzas cinceladas (Fernández Fuster, 1951: 72).

Posteriormente, F. Marco Simón (Marco Simón, 1976) recuperó la idea de Schulten y la desarrolló, más allá de su interpretación literal. En opinión de este autor, «hay que ver en las lanzas de las estelas bajoaragonesas un elemento de índole escatológica, asumidor de la pujanza y, en definitiva, de la heroización del difunto, para el que la guerra connotaría ya no sólo una cotidianidad sino una uirtus, sobrepasando de este modo la interpretación exclusivamente realista o concreta de estos monumentos» (Marco Simón, 1976: 85-86). Así, las lanzas no serían un numeral sino simplemente una abstracción simbólica de la guerra; no el número de guerreros vencidos o de batallas ganadas, sino la representación misma de la guerra o la victoria. F. Quesada se muestra de acuerdo en esta dirección (Quesada Sanz, 1994: 365) opinión que también nosotros compartimos. Lo cierto es que Marco Simón contaba ya con un número mayor de piezas gracias a nuevos hallazgos, especialmente los procedentes de El Palao (Alcañiz). Destaca especialmente una de esas piezas, con una decoración que presenta una escena de combate con paralelos importantes con la estela hallada en Tona (Barcelona). Se trata de una composición con un jinete armado con lanza y caetra. A los pies del caballo aparece otro guerrero, muerto o malherido, también pertrechado con caetra, que se le ha caído de la mano. A su alrededor figuran 3 aves rapaces, un cánido y una gran mano cortada. Por su parte, en la estela de Tona aparecen dos combatientes en liza, armados con palos o espadas. Uno de los combatientes sujeta la cabeza del otro y parece a punto de asestarle el golpe de gracia. Debajo del duelo aparece también un cánido. La escena podría ser más compleja, pero el fragmentado estado de la estela y la pérdida de gran parte de la misma lo impiden.

\section{LAS ESTELAS DE ESTILO BAJOARAGONÉS EN CATALUÑA}

La decoración que caracteriza al grupo del Bajo Aragón y que asimilamos a nuestro grupo de 4+2, es bastante homogénea. Una mera aproximación nos delata que todas ellas, salvo una, albergan su decoración en una única cara. Aparecen también representaciones de jinetes o infantes armados y, en unas pocas ocasiones, de guerreros caídos y símbolos relacionados con la victoria militar sobre el enemigo (manos cortadas). Pero es la presencia de lanzas, esgrafiadas o esculpidas, aquello que caracteriza al conjunto. Se trata de lanzas dispuestas verticalmente, una al lado de la otra, divididas frecuentemente en distintos grupos por franjas horizontales y dispuestas a distintas alturas. En ocasiones aparecen de forma individual colocadas en las esquinas o en los bordes del conjunto iconográfico. Pese a que algunas de ellas presentan el astil y el regatón, lo más común es que tan solo aparezca la moharra. El tercer elemento destacable del conjunto son las líneas en forma de cenefa que limitan y enmarcan la cara decorada de la estela. Se trata de motivos geométricos simples compuestos a menudo por dos líneas paralelas que albergan en su interior un trazo zigzagueante que en algunos casos aparece deformado, perdiendo angulosidad y convirtiéndose en ondas o meandros.

Contamos con cuatro ejemplos seguros en Cataluña que siguen esta pauta decorativa: Rubí, Tona y Sant Sebastià de la Guarda (2); y dos más, en Badalona, que integran lanzas verticales con otros motivos (epigráficos en un caso, decoración astral en el otro). Salvo en el caso de Rubí, las estelas se encuentran bastante fragmentadas y, siguiendo la pauta tradicional, fueron encontradas fuera de contexto. Aun así, la decoración no deja lugar a dudas sobre su parentesco con el grupo bajoaragonés. 


\section{LA ESTELA DE RuBÍ}

Se trata de una pieza de notables dimensiones $(148 \text { x } 39 \text { x } 26 \mathrm{~cm})^{5}$ y la mejor conservada de todo el grupo. Aun así, la parte inferior se ha perdido y a la superior le falta una esquina. Asimismo, presenta un fuerte desgaste en su lateral izquierdo así como un arañazo en la cara decorada producido en el momento de su hallazgo, en 1960, provocado por el arado de un tractor (Arís Puiggròs y García Herranz, 1984: 342). Todas sus caras son lisas, muy bien trabajadas pese a que tan solo una de ellas presenta decoración. Se trata de tres franjas de lanzas verticales. Cada una de estas franjas se encuentra separada de la inferior por una línea horizontal (levemente inclinada hacia la izquierda) que actúa de suelo donde se encuentran clavadas estas lanzas. Estas tres franjas albergan distinto número de lanzas que, además, parecen tener distintos tamaños (las de la franja central son más largas, mientras que las superiores son las más cortas). El estado actual de la pieza permite contabilizar 7 lanzas en la franja superior, 4 en la central y 4 más en la inferior, pero su estudio metrológico nos revela que probablemente fueron 8,5 y 5 respectivamente. Cabe destacar que esta decoración está esgrafiada en la estela, y no esculpida en bajorrelieve. La simplicidad y, en ocasiones, la poca precisión en los trazos de los motivos sorprenden en comparación con la buena factura en la talla de la estela. Estas diferencias nos sugieren que quizá no fueran las mismas manos aquellas que prepararon la losa de piedra y aquellas que la decoraron.

\section{Las estelas de Sant Sebastià de la Guarda}

En la costa central de la provincia de Girona se encuentra el poblado ibérico de Sant Sebastià de la Guarda (Palafrugell), ubicado en la cima de una colina que termina en un acantilado al mar. Se trata de un pequeño asentamiento sobre el cual se construyó, a partir del siglo XV n.e., un santuario con una atalaya y un faro, construcciones que han afectado de lleno el estudio de las estructuras ibéricas. A partir del análisis cerámico se ha establecido una continuidad de ocupación entre los siglos VI y I, con un mayor índice de actividad entre los siglos IV y III. Cabe señalar también la documentación de 27 silos de almacenaje en el interior del oppidum. Estos silos parecen tener una mayor utilización entre finales del siglo III y mediados del siglo II (Nolla et alii, 2010: 252). Es destacable, por último, la cercanía con la población de Llafranc, justamente a los pies del cerro, que alberga importantes vestigios de época romana a partir del siglo I (Barti et alii, 2004: 216).

Ambas estelas tampoco fueron encontradas en su contexto arqueológico original. La primera -denominada estela 1- fue hallada por casualidad en 1975, al desprenderse de uno de los muros del poblado ibérico que había quedado al descubierto en el margen del camino. La pieza había sido reutilizada como material de construcción, aunque se desconoce, por el momento, la cronología exacta de dicho muro. Sus medidas son 75 x 43 x $20 \mathrm{~cm}$, disminuyendo levemente hacia su parte inferior. En cuanto a su decoración, incisa, presenta dos hileras de lanzas. La franja superior está formada por 11 de ellas colocadas en paralelo. El astil, que no se distingue de la moharra por acanaladura alguna, se asienta sobre una línea horizontal a modo de suelo. La hilera inferior, con tan sólo dos lanzas, parece inacabada. Estas dos lanzas se concentran en el lado derecho de la estela, aunque sin llegar al extremo lateral definido por la hilera superior. El resto de la franja inferior está ocupado por una línea horizontal que discurre paralela a la línea de suelo superior. Pudiera parecer, como si de un manuscrito en cursiva se tratase, que

\footnotetext{
5 Todas las medidas, en adelante, indican altura, anchura y profundidad, en este orden.
} 


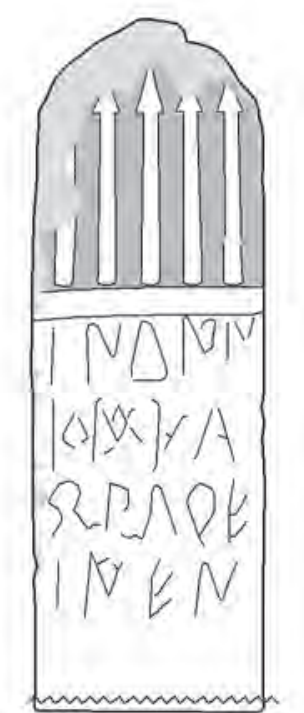

Estela 2 de Badalona

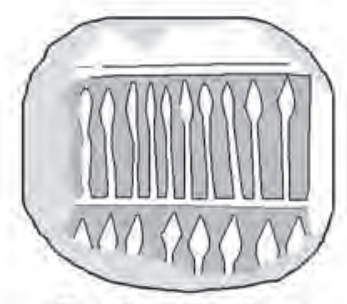

Estela 2 de Sant Sebastià de la Guarda

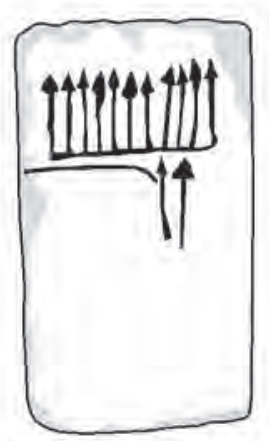

Estela 1 de Sant Sebastià de la Guarda

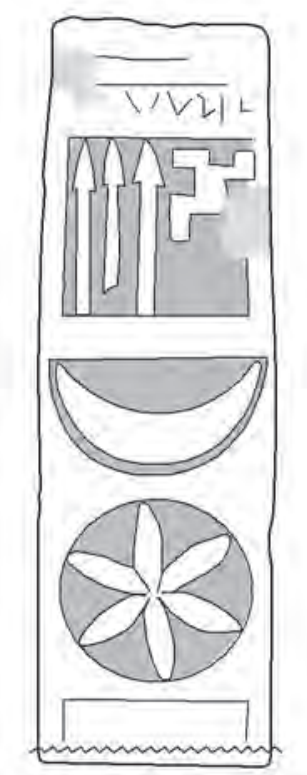

Estela 1 de Badalona

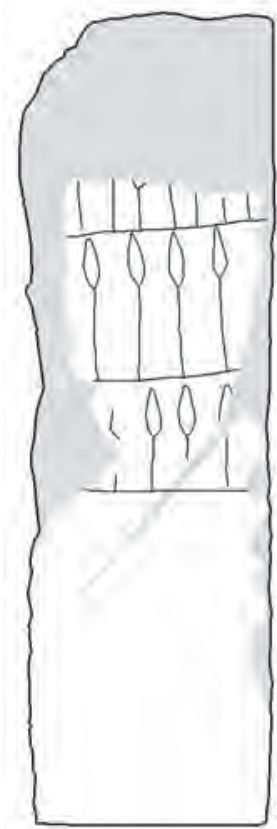

Estela de Rubi

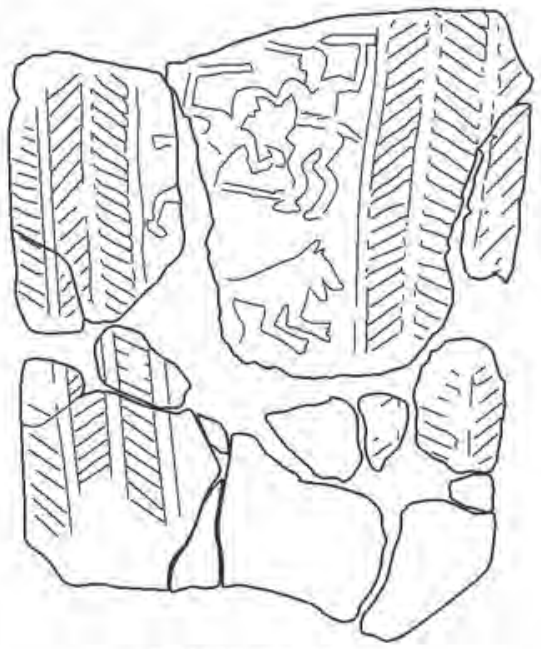

Estela de Tona

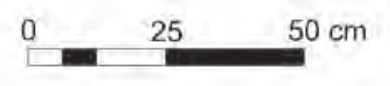

Figura 2. Croquis de las 4+2 piezas de estelas catalanas con decoración de tipo bajoaragonés. 
fuera una abreviatura, un modo esquemático de comunicar que en el resto de espacio inferior se repitiese la pauta de lanzas hincadas. A falta de otros paralelos, la interpretación queda abierta.

La segunda estela de Sant Sebastià de la Guarda fue localizada años más tarde, en 1983, cerca del santuario medieval, entre un montón de escombros y, por tanto, completamente descontextualizada. Al igual que la primera pieza, ésta fue recogida y salvaguardada por los colaboradores del Museo de Palafrugell. El estado actual de la pieza es casi circular, prueba de una reutilización posterior. Aun así, podemos restituir parcialmente su forma paralelepipédica original gracias a que aún conserva parte de los laterales y la cara superior. De esta forma sabemos que la pieza tenía una anchura de $53 \mathrm{~cm}$ y un grosor de $24 \mathrm{~cm}$. La altura máxima actual es de $47 \mathrm{~cm}$, aunque es obvio, atendiendo a su composición decorativa, que al menos era el doble de alta. En su cara frontal se pueden observar dos hileras de lanzas verticales, pero al contrario que las 2 piezas anteriores, están esculpidas en bajorrelieve. Todas ellas se disponen con las puntas hacia arriba y se encuentran separadas por una línea horizontal que hace las veces de base para el grupo superior. Desconocemos si esta estela albergaba más franjas en la parte inferior. En cualquier caso, actualmente se distinguen diez puntas de lanza completas en la hilera superior y ocho puntas en la inferior. En ambos casos no parece que hubiera más espacio lateral para albergar a más unidades en su estado original, salvo, quizá, una undécima en el lateral izquierdo de la hilera superior. Pese a que el esculpido de las lanzas es simple, ya que tampoco se distingue el astil de la moharra, los ejemplares de ambas hileras parecen ser distintos. Así, mientras que en la superior tienen puntas más pequeñas y en forma de hoja de laurel, en la inferior son de mayores dimensiones, de ahí su menor número en el mismo espacio. Cabe destacar que en las tres estelas catalanas con más de una hilera de lanzas verticales, siempre aparece un número superior de ellas en la franja superior.

En este ejemplar, además, se distingue un marco en la parte superior que parece pudiera envolver a todo el conjunto. Sin embargo, carece de decoración en forma de espina de pez o en cenefa, como en numerosos ejemplos aragoneses.

\section{LA ESTELA DE TONA}

El ejemplar hallado en 1915 en la población de Tona, en el interior de la provincia de Barcelona, constituye una de las piezas más singulares del arte ibérico en Cataluña. Su estado actual se encuentra fragmentado en cinco piezas (en el momento de su extracción contaba con 14 fragmentos) que, pese a todo, permiten conocer su anchura y grosor originales, aunque no así su altura (Garcés y Cebrià, 2003: 219). Las dimensiones en sus extremos máximos son 90 x 93 x $16 \mathrm{~cm}$, lo que la convierten en la pieza de más anchura y menos profundidad de nuestra muestra. Extraída también fuera de su contexto arqueológico original, esta pieza se ha relacionado tradicionalmente con el yacimiento de El Camp de les Lloses (Maluquer de Motes, 1982), una estación iberorromana en proceso de excavación, fechada entre los años 125 y 75 (Ñaco del Hoyo y Principal, 2012). Recientemente, I. Garcés y A. Cebrià, detallaban que su extracción se produjo, en realidad, en el contiguo paraje de Mas Riambau (Garcés y Cebrià, 2003: 214). Maluquer relacionó la estela con algunas sepulturas encontradas muy cerca del Camp de les Lloses, pero los datos relativos a esta posible necrópolis proceden de excavaciones sin metodología científica y no reúnen pruebas suficientes para establecer cronología alguna. Además, la zona donde se hallaron dichas tumbas es más cercana a la capilla del Barri y a la iglesia parroquial de Sant Andreu, santuarios ambos altomedievales, que al lugar donde se extrajo la estela (Duran et alii, 2008). Si bien los datos de que disponemos tienden a descar- 
tar su relación con esas sepulturas, en cambio sí que parece acertado vincular la estela con el Camp de les Lloses, situado a escasos $50 \mathrm{~m}$ de su lugar de extracción.

A diferencia de las demás estelas, la decoración de esta pieza no presenta lanza alguna. Aun así, la composición en bajorrelieve que presenta hay que vincularla con motivos muy similares hallados en estelas bajoaragonesas, especialmente con la estela de El Palao (Alcañiz) e incluso Palermo (Caspe). Asimismo, el marco que encierra la escena de la estela de Tona, con decoración en espina de pez, es también una de las características más comunes entre las estelas aragonesas. En este sentido cabe añadir la existencia de un fragmento de piedra, decorada con el mismo motivo, hallada hace unos treinta años en la misma localidad. Las reducidas dimensiones de la pieza $(34,5$ x 30,5 x $20 \mathrm{~cm})$ no permiten mostrar más decoración que el marco lateral en forma de spicatum, pero su trabajo es muy similar a la estela de Mas Riambau. Sabemos que no formaba parte del mismo monumento en base a la tipología de la piedra (se trata de gres calcáreo de tonalidad gris respecto a la arenisca rojiza de la anterior) y a la propia decoración, ya que esta presenta cuatro franjas de spicatum frente a las tres de Mas Riambau. Esta circunstancia ha llevado a plantear incluso la posibilidad de la existencia de un taller escultórico local (Garcés y Cebrià, 2003: 222).

En cualquier caso, el motivo principal que quiere transmitir la estela de Tona es la composición central formada por dos individuos en combate y la figura de un cánido en su parte inferior. La escena, sin ostentar un gran nivel de detalle, permite distinguir algunos elementos importantes en cuanto a los guerreros en liza. El individuo de la derecha, ligeramente por encima de su oponente, blande un arma en su mano izquierda. La calidad de la obra no permite distinguir de qué tipo de arma de mano se trata; bien podría ser un simple garrote o bien una espada. No obstante, una vaina colgando de su cinturón, nos remite a la segunda opción. Con su mano derecha parece coger por la cabeza a su oponente, el cual, armado idénticamente, quiere zafarse sin fortuna y está a punto de recibir el golpe de gracia. Intervienen también lo que pudieran ser dos lanzas, sin propietario alguno, que por falta de perspectiva podrían interpretarse como armas ya utilizadas por ambos contendientes antes de llegar al combate cuerpo a cuerpo. Una segunda interpretación propone que ambos individuos han sido heridos mediante una lanzada -en el vientre uno, en la cabeza el otro- y que el combatiente derrotado lleva, además, una caetra en la mano izquierda (Garcés y Cebrià, 2003: 221). Desde nuestro punto de vista, esta segunda interpretación nos parece errónea (figura 2).

En cuanto al cánido que aparece a los pies de los combatientes, ha sido interpretado tanto como un perro (Marco Simón, 1976: 88; Beltrán Lloris, 1996: 178) como un lobo (Garcés y Cebrià, 2003: 225), dado que el detalle de la figura no permite tal distinción. En la estela de El Palao (Alcañiz) aparece también un cánido y se ha propuesto que podría tratarse de perros, dado que este es un animal que tradicionalmente se ha asociado a los miserables o a los moribundos y no es extraño encontrar enterramientos humanos acompañados de perros o caballos (Marco Simón, 1976: 87). Sin embargo, nosotros somos más partidarios de creer que se trata de un lobo y no de un perro, posibilidad que ya apuntaba F. Quesada (Quesada Sanz, 2000: 101). El lobo es un elemento muy común en el arte ibérico, tanto en escultura como en pintura u orfebrería y personifica un variado elenco emociones, prácticas, e incluso deidades, vinculadas a la guerra, la muerte y al mismo tránsito hacia el más allá (Blázquez, 1977; González Alcalde y Chapa Brunet, 1993; González Alcalde, 2006). Son frecuentes las escenas pintadas sobre cerámica del llamado estilo narrativo, u Oliva-Llíria donde, un héroe lucha contra un carnassier de grandes fauces (Aranegui Gascó y Pla Ballester, 1979: 84-85); igualmente, es de sobra conocido el disco-coraza del guerrero ibero esculpido de Elche, que presenta también la cara de este animal en actitud amenazante. También el NE peninsular cuenta con un buen ejemplo en este sentido como es la pátera de Tivissa, en la cual la cabeza de un lobo preside 
este objeto de culto (Blázquez, 1977: 221-241). En conjunto, la escena de la estela realza así el carácter guerrero del difunto mediante el combate de los dos contendientes, heroizándolo, a la vez que muestra su paso hacia la muerte, o incluso su apoteosis, a través del lobo.

En cuanto a la cronología se refiere, Maluquer de Motes, basándose en datos poco fiables procedentes de la necrópolis anteriormente citada, fechó la estela entre los siglos IV-III (Maluquer de Motes, 1982). Posteriormente, Garcés y Cebrià han avanzado esta fecha hasta los siglos III y II (Garcés y Cebrià, 2003: 227).

\section{Estelas de BADALOnA}

Caso aparte, por su singularidad, merecen las estelas encontrados bajo en casco urbano de la actual Badalona, la Baetulo romana. Todas ellas, tres, fueron encontradas fuera de contexto original, pero en dos lugares distintos. La primera de ellas fue localizada en 1879 en Can Peixau $^{6}$ (Carreras Candi, 1923). Su decoración incluye varios elementos iconográficos de gran interés, que pueden dividirse en tres conjuntos claramente distinguibles. Así, en la parte inferior se encuentra una luna creciente y una roseta de 6 puntas sobre un círculo (símbolo, este último, que también encontramos en algunos ejemplos aragoneses). Encima de este grupo, un marco encierra 3 lanzas verticales dispuestas a la izquierda de una esvástica. Finalmente, la parte superior de la pieza alberga un epígrafe en caracteres ibéricos.

Las otras dos estelas badalonesas fueron encontradas en el año 2000, durante el transcurso de las excavaciones realizadas en la plaza Font i Cussó. Esta vez, las piezas habían sido reutilizadas como losas para tapar el colector del cardo máximo de la ciudad romana. Una de ellas presenta tan solo un epígrafe ibérico, analizado minuciosamente por J. Velaza (Comas et alii, 2001), sin más decoración. La segunda pieza, sin embargo, alberga en su tercio superior un nuevo conjunto de lanzas verticales. Se trata de cinco lanzas, realizadas en bajorrelieve, de las cuales tan sólo una se conserva en toda su longitud. El resto carece de sus puntas, de forma parcial o total, debido a la mala conservación de la pieza, destrucción que pudo realizarse en el mismo momento de reutilización en época romana. Los dos tercios inferiores están ocupados por cuatro líneas de texto ibérico. A través de los epígrafes de ambas estelas se ha propuesto una posible vinculación entre ellas. El texto de la primera pieza ha sido traducido por «(De o Para) Nalbebiur», mientras que en la segunda se propone «(De o Para) Bantui, hijo de Nalbebiur» (Comas et alii, 2001: 298). Si dicha relación fuera realmente de parentesco, tal y como parece ser, estaríamos ante un ejemplo único dentro del mundo ibérico. Y es también a partir de la epigrafía que sus autores aproximan una datación para estos ejemplares, que no es otra que entre los años 150 y 75 (Comas et alii, 2001: 295). A tenor del lugar donde fueron encontradas estas estelas, el cardo máximo de una ciudad romana, debieron de ser trasladadas hasta el colector no mucho después de la fundación de la ciudad, es decir, a lo largo del siglo I. Por tanto, la fecha del año 75 como término antequem nos parece adecuada. Sin embargo, resulta evidente que estas losas no fueron talladas para cumplir esa función, sino que perdieron su significado y emplazamiento original tiempo atrás, y más lejos aún se ubicaría el momento de su erección. Podríamos, incluso, estar delante de un pequeño ejemplo de damnatio memoriae por parte de Roma, pues no deja de sorprender el hecho que un monumento en memoria de un difunto indígena se convierta, en menos de 50 años, en una losa de alcantarillado de una ciudad fundada por la nueva potencia dominante.

6 También conocida con el nombre del barrio badalonés actual, Llefià. 


\section{LA RELACIÓN DE LAS ESTELAS CATALANAS CON LAS ESTELAS BAJOARAGONESAS}

Mediante la descripción de las 4+2 estelas encontradas en Cataluña decoradas al estilo bajoaragonés, queda patente la similitud con los ejemplares localizados en esa región. Si bien las estelas orientales han sido tratadas ampliamente en la bibliografía, los estudios que indaguen sobre la relación de este grupo con las estelas catalanas, son muy escasos (Quesada Sanz, 2000; Garcés y Cebrià, 2003). Parece razonable pensar que existe algún tipo de vínculo entre ambos grupos, más aun cuando el foco principal se encuentra en una zona geográficamente tan reducida y los ejemplos de Cataluña, en cambio, están mucho más dispersos. Como hemos visto, se han realizado unos pocos estudios sobre las estelas catalanas de forma individual, especialmente desde un punto de vista arqueológico; sin embargo nos parece necesario afrontar esta cuestión desde un punto de vista global y con perspectiva histórica.

La decoración de las estelas en ambos grupos -catalán y aragonés-, se caracteriza, pues, por la presencia de lanzas. Hay quien ha querido distinguir la tipología de estas lanzas con tal de precisar mejor la cronología. Así, en ocasiones se ha planteado que pudiera tratarse de lanzas tipo La Tène II y III (Cabré, 1923: 635), de faláricas o soliferrea (Marco Simón, 1976: 84), de puntas de tipo hoja de laurel o triangulares (Badia Homs, 1988: 11), pero lo cierto es que la diversidad de tipos queda bien patente a medida que la muestra aumenta, incluso dentro de la misma pieza, circunstancia que nos invita a pensar que realmente no hacen referencia a una tipología única o concreta. Más bien parece tratarse simplemente de la esquematización de un arma de asta y de su plasmación sobre piedra. Sin duda, sus escultores tendrían un modelo a seguir, pero distintas manos las representaron de distintas formas. Quizá resulte mucho más relevante el hecho de que estas lanzas siempre se encuentren de modo vertical, agrupadas en distintas franjas, dispuestas de forma paralela y muy frecuentemente con líneas horizontales que separan ambos conjuntos. Así se presentan todos los ejemplos catalanes, salvo el caso de Tona, que no tiene ninguna lanza en el fragmento conservado (lo cual, debemos recalcar, no significa que no las tuviera en su forma completa y original) y la gran mayoría de los ejemplos aragoneses con lanzas. Ya hemos comentado las similitudes de la estela de Tona con ejemplos aragoneses en cuanto a su decoración con guerreros y cánido, y también por lo que respecta a la cenefa que enmarca el conjunto. Incluso se pueden observar grandes similitudes en la conceptualización y la representación de las figuras humanas en las estelas de Tona, Palermo, Camino de Santa Ana, Sant Antoni de Calaceit y El Palao. Dado que no se han hallado testimonios sobre estela con estos mismos motivos decorativos en ningún otro lugar, la relación entre ambos grupos parece clara.

Sin embargo, cabe destacar que en los casos de Rubí y de la estela 1 de Sant Sebastià de la Guarda, la factura de su decoración es mucho más simple y menos cuidada respecto a sus paralelos aragoneses. El trazo vertical de las lanzas -que es inciso, no en bajorrelieve- es irregular y su longitud no es homogénea, ni siquiera dentro de la misma franja; las líneas horizontales que separan los grupos de lanzas están inclinadas, caen claramente hacia la izquierda. Carecen de cualquier tipo de marco, a diferencia de la estela 2 de Sant Sebastià de la Guarda y de la de Tona. Este trazo poco delicado destaca todavía más si lo comparamos con la buena factura de la piedra que los alberga.

\section{CRONOLOGÍA}

Parece haber un notable acuerdo entre los investigadores en fechar la erección de las estelas bajoaragonesas entre los siglos II-I (Fernández Fuster, 1951; Marco Simón, 1976; Beltrán 
Lloris et alii, 2000: 48), si bien hay quien retrasa este fenómeno entre los siglos III y II (Cabré, 1923; Beltrán Lloris, 1996:597).

Como ya hemos señalado, las estelas catalanas adolecen del mismo problema: no se ha extraído ninguna de ellas de su contexto original. Aun así, los investigadores encargados de su estudio también tienden a ubicar estos monumentos entre los siglos II y I (Badia Homs, 1988: 17; Comas et alii, 2001; 295; Bencomo Mora et alii, 1985), pese algunas excepciones (Maluquer de Motes, 1982; Garcés y Cebrià, 2003). Debemos hacer hincapié en que, en no pocas ocasiones, especialmente en estudios antiguos, se determinó esta cronología en base a su comparación con las estelas turolenses, pero también es cierto que los yacimientos más próximos a sus lugares de extracción documentan una fuerte actividad en estos momentos. Así, la estela de Rubí se encontró muy cerca del discutido poblado de Can Fatjó, la mayor parte de materiales del cual corresponden al Ibérico Final (Arís et alii, 1989). Igualmente, las piezas de Sant Sebastià de la Guarda corresponden sin duda a los aledaños del poblado; un poblado que alberga también numerosos silos que dibujan un pico de actividad entre finales del siglo III y mediados del siglo II (Nolla et alii, 2010: 252). En el caso de Tona, las exploraciones superficiales en la zona de Mas Riambau aportaron materiales de amplia cronología y sus investigadores han propuesto una cronología alta para la estela (Garcés y Cebrià, 2003: 215). Sin embargo, nos parece determinante el yacimiento de El Camp de les Lloses, fechado entre el 125 y el 75 (Ñaco Del Hoyo y Principal, 2012). Las estelas de Badalona, por su parte, han sido ubicadas entre el 150 y el 75 (Comas et alii, 2001: 295), y si bien se encontraron reutilizadas en la ciudad romana de Baetulo, es más probable que estuvieran relacionadas con el cercano poblado layetano de Turó d'en Boscà (Badalona). Dicho yacimiento ha sido fechado entre mediados del siglo IV y comienzos del siglo I. Así pues, aun careciendo de las referencias cronológicas aragonesas, nos inclinamos a pensar que el fenómeno de erigir estelas del tipo aragonés en Cataluña se produce entre la segunda mitad del siglo II e inicios del siglo I.

A nivel geográfico destaca la dispersión de los ejemplares catalanes ante la concentración de los aragoneses. Es aquí donde la problemática se complica debido a que nuestra muestra de 4+2 aparece sobre los territorios de tres pueblos ibéricos: layetanos (Rubí y Badalona), ausetanos (Tona) e indiketes (Sant Sebastià de la Guarda). Se ha apuntado la posibilidad que tanto Rubí como Sant Sebastià de la Guarda, formasen parte del pueblo ausetano (Quesada Sanz, 2000: 103), prolongando las fronteras de este pueblo hacia el este y el sur y así englobar todos los ejemplares bajo una misma órbita. Esta posibilidad viene además respaldada por el hecho que el grupo de estelas bajoaragonesas se incluyen dentro del territorio de los llamados «ausetanos del ebro» u ositanos (Burillo Mozota, 2002). Sin embargo, la distribución de pueblos del nordeste peninsular, especialmente desde finales del siglo III, es una cuestión ampliamente tratada y pese a no establecer unos límites étnicos inamovibles, los ejemplares de Rubí y Sant Sebastià de la Guarda se adscriben claramente dentro de los territorios de layetanos e indiketes respectivamente. Desde nuestro punto de vista, resulta más fácil explicar esta dispersión mediante el movimiento de pequeños grupos de individuos o de tropas, como, de hecho también apuntaba el propio F. Quesada (Quesada Sanz, 2000: 104), que no adscribiendo las seis estelas a un solo pueblo.

En este sentido, la posibilidad que los autores de la elaboración -o el encargo- de estas estelas fuesen algún tipo de tropa militar, parece muy apropiada. Así, la dispersión de las estelas catalanas cobra sentido en el momento en que se relaciona con una de las principales vías de comunicación del Ibérico Final: la vía Herakleia. En efecto, todos los lugares donde se ubican estas estelas coinciden en poseer una ubicación geoestratégica y visual muy importantes. Rubí

\footnotetext{
7 Posteriormente rectificó y propuso la cronología baja.
} 
se sitúa a los pies mismos de esta vía, además de situarse muy próximo a otra importante ruta de penetración al interior de Cataluña como es el río Llobregat. Tona se ubica en el paso de montaña entre la vía Herakleia y la llanura de Vic y los Pirineos. Precisamente en este lugar se documenta una calzada romana, la vía de Manius Sergius, fechada hacia el año 110 a.n.e. y atestiguada por el descubrimiento de varios miliarios (Padrós, 2010: 234). Sant Sebastià de la Guarda, por su parte, se encuentra más al norte, a unos $30 \mathrm{~km}$ del camino de Hércules, pero su contacto con el mar, un resguardado fondeadero y unas buenas conexiones terrestres con el interior, lo convierten también en un punto de gran interés. Por último, desconocemos la procedencia exacta de las estelas de Badalona, pero dadas sus características, es probable que se erigieran en el área de la futura ciudad romana, a los pies del poblado de El Turó d'en Boscà. Un ramal de la futura vía Augusta discurre por la población y es muy probable que en época ibérica ya fuera un camino bastante concurrido, dado que conecta una gran número de oppida situados en la costa (Zamora et alii, 2001). Además, en ese punto se encuentra también el río Besòs, el cual cruza la sierra litoral y conecta la costa con el interior y la vía Herakleia.

\section{SOBRE EL COMENTARIO ARISTOTÉLICO}

El comentario de Aristóteles (Pol. VII, 2, 11; 1324b) apuntado por Schulten aportó un valioso punto de vista. El fragmento en sí informa sobre la práctica ibérica de clavar lanzas alrededor de la tumba de un guerrero caído y se inserta en un fragmento en el cual el filósofo macedonio enumera una serie de prácticas rituales de algunos pueblos extranjeros relacionadas con la guerra ${ }^{8}$. Aristóteles escribe a mediados del siglo IV a.n.e. y, aunque es posible que tuviera contacto directo con los iberos enviados a Grecia por el tirano Dionisio I de Siracusa, es más probable que estos datos le llegasen de manera indirecta. Fuera a través de su maestro Platón, como sugiere F. Quesada (Quesada Sanz, 1994), o de mercaderes o comerciantes, es muy posible que esta información proviniese de mercenarios iberos contratados por Esparta, Siracusa o Cartago. Por un lado, parece claro que la noticia procede de un ambiente fundamentalmente militar, ya que se ensalza y honra la virtud marcial del difunto para ejemplo de todos. Es, además, la única característica que se destaca: en esta práctica, su reconocimiento mediante la señalización de su tumba a través de lanzas hincadas corre pareja a sus logros en el campo de batalla. Por otro lado, carecemos de noticias sobre movimientos de iberos fuera de la península Ibérica en los siglos IV y III que no fueran contingentes de mercenarios contratados por poleis griegas (X. HG 7.1.20, 28; D.S. 15.70). Aunque a buen seguro viajarían mercaderes o buscavidas iberos a otros puertos del Mediterráneo, es mucho más plausible que esta noticia llegara a oídos de Aristóteles procedente de alguno de estos contingentes militares. Podemos, pues, relacionar esta práctica funeraria con el mundo militar ibérico.

Como hemos señalado anteriormente, parece que en algún momento se produjo una evolución de esta práctica hacia su petrificación (Quesada Sanz, 1994; Marco Simón, 1976). Es decir, el ritual del siglo IV de hincar lanzas en el suelo alrededor de la tumba del difunto, fue en algún momento sustituida por el tallado de una estela en la cual se esgrafiaron o cincelaron lanzas verticalmente. El ritual se petrificó. A tenor del estado actual de las investigaciones, parece ser que este fenómeno se produjo con exclusividad en el Bajo Aragón. En el caso de

8 El fragmento en concreto dice así: "Entre los iberos, pueblo belicoso, se elevan tantos obeliscos en torno a la tumba de un hombre como enemigos haya aniquilado” (traducción de Manuela García Valdés). Estos “obeliscos” hay que interpretarlos como lanzas y no como piedras hincadas según la mayoría de autores (SCHULTEN, 1912; QUESADA SANZ, 1994: 361-363). 
Cataluña, con unos pocos ejemplares localizados de forma dispersa, creemos que la explicación corre en otro sentido.

\section{AUXILIA IBÉRICOS BAJOARAGONESES EN CATALUÑA SEPTENTRIONAL}

Parece claro que el origen y el foco de desarrollo de la erección de estelas funerarias con lanzas y motivos bélicos estuvo en el Bajo Aragón, territorio bajo dominio de los ausetanos del Ebro según algunos autores (Burillo Mozota, 2002), de edetanos y/o sedetanos según otros 9 Sin embargo la presencia de varias estelas con motivos claramente relacionables con los anteriores en Cataluña, todas ellas al norte del Ebro, requiere una explicación. En este sentido, no creemos posible la aparición de este fenómeno funerario en ambas zonas de forma independiente, más aun teniendo en cuenta que las estelas catalanas se reparten bajo los territorios de tres pueblos distintos, layetanos, ausetanos e indiketes. Así pues, parece mucho más plausible centrarse en una línea de investigación que explique la aparición de estas estelas en Cataluña como resultado de una migración de individuos procedentes de ese foco aragonés.

Atendiendo al tipo de decoración con motivos de carácter bélico que presentan todas ellas, y en relación con el fragmento aristotélico comentado anteriormente, creemos que el difunto debiera tratarse de un personaje de rango militar. Parece plausible proponer que aquellos a quienes se erigieron las estelas catalanas fueran caudillos de algún tipo de tropa procedente del Bajo Aragón. Estos caudillos no viajarían solos sino al mando de cierto número de tropas que, al menos en parte, compartirían su misma procedencia. Desde este punto de vista, estas tropas reproducirían los monumentos funerarios propios de su tierra allí donde tuvieran sus campamentos o centros de reclutamiento. Esto nos lleva a la ubicación geográfica de los enclaves donde se han recuperado estas estelas. Como hemos visto, todos ellos están ubicados a los pies de las principales vías que comunican el área ibérica del valle medio del Ebro con el litoral catalán y el sur de la Galia. De hecho, en el caso de El Camp de les Lloses de Tona, sus investigadores piensan que se trata, efectivamente, de un punto de reclutamiento o abastecimiento de tropas auxiliares romanas (Ñaco Del Hoyo y Principal, 2012). Creemos, efectivamente, que estas estelas son el testimonio del paso de tropas ibéricas enroladas por Roma, procedentes del área bajoaragonesa entre mediados del siglo II y comienzos del siglo I, quizás más concretamente entre el 130 y el 90. En cuanto a la naturaleza de estas tropas, bien pudiera tratarse, teniendo en cuenta la cronología, de auxiliares hispanos. Sin embargo no puede descartarse la posibilidad que el mercenariado fuese un elemento destacado en este mismo periodo (Cadiou, 2008: 662). ¿¿ué ocurre en ese momento? No nos planteamos porqué se originó este fenómeno en el Bajo Aragón, sino la razón por la cual este mismo fenómeno emigró puntualmente sobre una gran área de dispersión en Cataluña.

Con la caída de Numancia en el 133 y el fin de la Guerra Celtibérica se abrieron nuevos frentes en la política romana respecto al norte de Hispania. Por un lado, había que asegurarse la gestión de los territorios celtibéricos ocupados, los cuales, por cierto, serían objeto de una segunda campaña contra sus oppida principales (Ap. Ib., 99-100). Por otro lado, este es un momento de máximo esfuerzo bélico por parte de la República romana debido a los numerosos -y distantes entre sí- frentes de batalla que se le plantean, circunstancia que se pone de manifiesto con el alistamiento público de voluntarios al ejército de Mario para partir hacia Numidia en el

\footnotetext{
9 Al respecto existen contradicciones importantes en las fuentes antiguas al atribuir a este territorio una u otra etnia. Sin embargo, recientemente se tiende a distinguir entre sedetanos y edetanos a partir del siglo III. En esta cuestión, ver BURILLO MOZOTA, 2001; RUIZ y MOLINOS, 1993:255-256.
} 
107 (Sal. Guerra de Yugurta, 86). Además de la guerra en el norte de África, los principales conflictos a los que debe hacer frente Roma en el periodo 120-80 son la defensa de Narbo y el sur de la Galia frente a cimbrios y teutones (114-102), la ya mencionada II Guerra Celtibérica (98-92), el Bellum sociale (91-89), la guerra contra Mitrídates VI (89-63), la lucha por el poder de Sila (88-82) y, posteriormente, de sus partidarios contra Sertorio (83-72). Tal situación, sin duda obligó a Roma a reclutar bajo distintas formas de coerción, alianza o pago a tantas tropas militares como le fuera posible ${ }^{10}$. A nivel geográfico, podemos relacionar el envío de tropas hispanas hacia el norte peninsular y sur de la Galia con las luchas en el frente cimbrio-teutón. Sin duda, las tropas bajoaragonesas que habrían erigido las estelas encontradas en Cataluña no serían los únicos contingentes enviados a tal fin, pero quizás sí los únicos en dejar testimonio material de su paso. O quizás no.

Gracias al estudio numismático realizado en yacimientos como el Camp de Les Lloses (Tona) o Can Fatjó (Rubí) podemos testimoniar la presencia de tropas hispanas reclutadas en distintos puntos del nordeste peninsular y rastrear su recorrido hasta cierto punto. Así, Fernando López Sánchez ha demostrado recientemente el envío de tropas hispanas a Italia hacia el año 90 (López Sánchez, 2010). Si aceptamos como válida la cronología baja de las monedas ibéricas planteada por dicho autor, las monedas con jinetes con palma encontradas en Rubí y en Tona, dan buena cuenta del tránsito de tropas hispanas hacia el norte, siguiendo la vía Herakleia, alrededor del año $100^{11}$. De este modo, las monedas con jinetes con palma serían entregadas a los auxiliares hispanos en los centros de reclutamiento romanos, pequeños enclaves dispersos en el territorio con funciones eminentemente logísticas.

La segunda mitad del siglo II es un periodo relativamente mal conocido a nivel arqueológico en Cataluña. Una gran cantidad de oppida ibéricos son abandonados durante el primer cuarto de siglo y las primeras fundaciones romanas -de estatus jurídico diverso- no parecen erigirse antes del año 100. Existen algunos asentamientos que aparecen en esta época, como Can Tacó (Montornès del Vallès, Barcelona), quizá Ca l'Arnau (Cabrera de Mar, Barcelona), o el propio Camp de les Lloses (Tona, Barcelona), pero todos ellos coinciden en unas reducidas dimensiones (menores de 1ha) y en una muy breve ocupación en el tiempo. Can Fatjó y Sant Sebastià de la Guarda forman parte de una minoría de asentamientos indígenas que en estas latitudes sobreviven al siglo II. También El Turó d'en Boscà mantiene su actividad hasta principios del siglo I (Zamora et alii, 2001: 225). En este sentido, creemos apropiado vincular los yacimientos donde se han localizado las estelas con centros de reclutamiento y aprovisionamiento de tropas auxiliares romanas. Dichas estaciones actuarían como centros logísticos dirigidos por Roma a través de los cuales tropas hispanas serían enviadas allí donde fuera necesario. Su proximidad a importantes vías de comunicación, tanto terrestres como marítimas, añade argumentos de peso a esta hipótesis. Por otro lado, la pervivencia de estos poblados indígenas quizá pueda explicarse a través de su amortización romana en centros de este tipo.

10 Es el caso, por ejemplo, de la turma salluitana atestiguada en el Bronce de Ascoli, un grupo de 30 jinetes procedentes del valle medio del Ebro que fueron reclutados en Salduie para luchar junto a Roma en la Guerra Social y que recibieron, en reconocimiento a sus méritos, la ciudadanía romana (PINA POLO, 2003: 198).

11 Tan solo contamos con dos ejemplares monetales en Sant Sebastià de la Guarda, ambos ases de bronce con la leyenda Untikesken y decorados en el anverso con un toro y un jinete respectivamente (BARTI et alii, 2004: 167). Entre los ejemplares de Rubí que sobrevivieron a la Guerra Civil destacan: un cuadrante y un as de bronce de Untikesken, con león y pegaso en el anverso respectivamente; 3 monedas de bronce procedentes de Ebusus con león embistiendo; un semis y dos ases de bronce de Cese con caballo y jinete con palma respectivamente; un as de bronce de Ilturo con jinete con palma; un denario de Bolskan con jinete con palma; dos ases de Bolskan con jinete con lanza (FONT, 2010). 


\section{CONCLUSIONES}

Las estelas ibéricas con lanzas encontradas en Cataluña deben relacionarse con el grupo concentrado en el Bajo Aragón. Su particular y bien definida decoración, bajo unos estrictos parámetros iconográficos, enlaza ambos grupos. Partiendo de la escasa probabilidad que el fenómeno apareciese en dos áreas distintas en similares cronologías, la cuestión debe resolverse a través del movimiento demográfico y, por ende, cultural. La falta de contexto arqueológico original impide su datación absoluta así como su funcionalidad. Sin embargo, gracias a una serie de indicios iconográficos, numismáticos, literarios y al material relacionado con sus yacimientos más cercanos, podemos establecer algunas hipótesis de trabajo.

Además, la dispersión sobre el territorio de las estelas catalanas, que contrasta con la concentración del grupo madre, parece indicar que se trata de grupos reducidos de individuos. En este sentido, creemos ver en estos monolitos, el testimonio material del paso de tropas militares hispanas contratadas por Roma hacia el frente de la Galia meridional, alrededor del año 100. La iconografía, indudablemente de carácter bélico, pone de manifiesto la naturaleza o función de las personas por quien o para quien fueron erigidas. El comentario aristotélico sobre la costumbre ibérica de hincar lanzas alrededor de la tumba de un difunto guerrero subraya su carácter funerario/honorífico. Por otro lado, su localización en estaciones iberorromanas bien comunicadas con las principales vías de comunicación entre la Celtiberia, el nordeste peninsular y el sur de la Galia nos indica una concurrencia de individuos en el área bajo dominación romana. Este tránsito bien podría dirigirse al frente de guerra cimbrio-teutón de finales del siglo II. La numismática, como se ha apuntado, parece corroborar dicha hipótesis. Por último, pese a la parquedad de las fuentes literarias en este contexto, Livio nos menciona que fueron los celtiberos quienes detuvieron el avance de cimbrios y teutones (Liv., Per. 67). Así, la participación de tropas hispanas en el nordeste peninsular aparece bien atestiguada. Si bien es cierto que el autor latino hace referencia a los celtiberos, la proximidad geográfica del Bajo Aragón con la Celtiberia, podría haber confundido a las fuentes de las que bebió Livio.

Así pues, en esencia, creemos posible poder vincular las estelas decoradas con motivos de carácter bélico con el movimiento de tropas auxiliares de procedencia bajoaragonesa, hacia el sur de la Galia. Creemos que la funcionalidad de la mayor parte de estas piezas fue de carácter funerario. La estela de El Camp de les Lloses (Tona), por su parte, cabría identificarla con un monumento de carácter honorífico a tenor de su decoración y, muy especialmente, de sus proporciones. En cualquier caso, el significado de todas ellas alude a la muerte y glorificación de un líder guerrero, posiblemente del caudillo de estas tropas auxiliares. Tras la muerte de éste, con sus despojos o sin ellos, sus tropas habrían erigido un monumento en su memoria mediante la práctica ritual propia de su pueblo. Ante la imposibilidad de trasladarse a sus oppida de origen, estas tropas debieron preferir erigir el monumento en los cuarteles de reclutamiento donde tenían su base de operaciones mientras durase su servicio a Roma.

Sin embargo, no debemos descartar la opción que su función fuera de hito o mojón de carácter informativo y que, en lugar de señalar la tumba de un caudillo, indicase la zona de estacionamiento de esa tropa en los alrededores del centro de reclutamiento romano. En este sentido, se ha apuntado la claridad con que tropas auxiliares hispanas se distinguían entre ellas en función de su procedencia (Roldán Hervás, 1974: 265), de modo que no es absurdo pensar que estas estelas actuaran como indicadores del campamento de las tropas procedentes del Bajo Aragón. Se observa, pues, que pese a su distinta significación, esta tesis que les otorga a las estelas un carácter étnico-campamental, no difiere en su desarrollo y concepción de la propuesta de tipo funerario; ambas teorías atestiguan de igual modo la presencia -o el tránsito- de este tipo de tropas bajoragonesas hacia el sur de la Galia. 


\section{BIBLIOGRAFÍA}

Araneguí Gascó, C.; Pla Ballester, E. (1979): La cerámica ibérica, La Baja época de la cultura ibérica. Actas de la mesa redonda celebrada en conmemoración del décimo aniversario de la Asociación Española de Arqueología, Madrid: 73-114.

Arís Puiggròs, R.M.; García Herranz, C. (1984): Excavacions en Can Fatjó (III Part), Butlletí del Grup de Col-laboradors del Museu de Rubí, 15: 343-345.

Arís, X.; Margenat, F.; Moro, A.; Vilalta, J. (1989): Delimitació del sòl arqueològic ibèric i romà del barri urbà de Rubí. Segles V aC a V dC, Actes de la XXXII Assemblea Intercomarcal d'Estudiosos. Rubí 18-19 octubre 1986. Any del Mil·lenari: 101-110.

Badia Homs, J. (1988): Dues esteles ibèriques de Sant Sebastià de la Guarda (Llafranc, Palafrugell), Estudis del Baix Empordà, 7: 5-18.

Barti, A.; Plana, R.; Tremoleda, J. (2004): Llafranc romà. Ajuntament de Palafrugell, Girona.

Beltrán Lloris, M. (1996): Los iberos en Aragón. Caja de Ahorros de la Inmaculada Concepción, Zaragoza.

Beltrán Lloris, F.; Martín Bueno, M.; Pina Polo, F. (2000): Roma en la Cuenca Media del Ebro. La romanización en Aragón. Caja de Ahorros de la Inmaculada Concepción, Zaragoza.

Bencomo Mora, C. et alii. (1986): Aproximació a la història de Rubí. Ajuntament de Rubí, Rubí.

Blázquez, J.M. (1977): Imagen y mito. Estudios sobre religiones mediterráneas e ibéricas. Ediciones Cristiandad, Madrid.

Bosch Gimpera, P. (1923): Les investigacions de la cultura ibèrica al Baix Aragó, Anuari de l'Institut d'Estudis Catalans: 1915-1920: 641-671.

Burillo Mozota, F. (2001): Etnias y poblamiento en el área ibérica del Valle Medio del Ebro: sedetanos y edetanos, Berrocal-Rangel y Gardes, P. (eds) Entre celtas e iberos: las poblaciones protohistóricas de las Galias e Hispania: 187-200.

Burillo Mozota, F. (2002): Propuesta de una territorialidad étnica para el Bajo Aragón: los ausetanos del Ebro u Ositanos, Kalathos, 20-21: 159-187.

Cabré Aguiló, J. (1923): Esteles ibèriques ornamentades del Baix Aragó, Anuari de l'Institut d'Estudis Catalans: 1915-1920: 629-641.

Cadiou, F. (2008): Hibera in terra miles. Les armées romaines et la conquête de l'Hispanie sous la République (218-45 av. J.-C.). Casa de Velázquez. Madrid.

Carreras Candi, F. (1937): L’estela ibèrica de Badalona, Butlletí del Centre Excursionista de Catalunya, 503: 92-99.

Duran, M.; Mestres, I.; Principal, J. (coord.) (2008): Les col-leccions de l'exposició permanent del Camp de les Lloses. Ajuntament de Tona, Tona.

Fernández Fuster, L. (1951): Las estelas ibéricas del Bajo Aragón, Seminario de Arte Aragonés, 3: 61-76.

Font i Urgell, J. (2010): Monetari iber i iberoromà del Museu de Rubí, Butlletí del Grup de Col·laboradors del Museu de Rubí, 55: 2-10.

Garcés, I. (1996): La estela ibérica de El Pilaret de Santa Quitèria (Fraga, Huesca). Una revisión a los cien años de su descubrimiento, Kalathos, 15: 35-55.

Garcés, I. Cebrià, A. (2003): L’estela ibèrica de Tona, Pyrenae, 33-34: 211-232.

González Alcalde, J.; Chapa Brunet, T. (1993): "Meterse en la boca del lobo". Una aproximación a la figura del "carnassier" en la religión ibérica, Complutum, 4: 169-174.

González Alcalde, J. (2006): Totemismo del lobo, rituales de iniciación y cuevas-santuario mediterráneas e ibéricas, Quaderns de Prehistòria i Arqueologia de Castelló, 25: 249-269.

Izquierdo Peraile, I. (2000): Monumentos funerarios ibéricos: los pilares-estela. Servicio de investigación prehistórica, Serie de trabajos varios, 98. Valencia.

López De Los Mozos, J.R. (2002): La estela y la muerte, Actas del VII Congreso Internacional de Estelas Funerarias: Santander, 24-26 de octubre de 2002, Vol. 1: 33-72.

López Sánchez, F. (2010): Moneda ibérica y gens mariana (107-90 a.C.), Gladius, 30: 171-190.

Maluquer De Motes, J. (1982): Notes sobre la formació del protagonisme dels ausetans, Ausa, 10: 251259.

Marco Simón, F. (1976): Nuevas estelas ibéricas de Alcañiz (Teruel), Pyrenae, 12: 73-90.

Marco Simón, F.; Baldellou, V. (1976): El monumento ibérico de Binéfar (Huesca), Pyrenae, 12: 91116. 
Marco Simón, F.; Royo Guillén, J.I. (2012): Iconografía entre la Primera Edad del Hierro y la Romanización: nuevos documentos y nuevas lecturas, Belarte, M.C. et alii. (ed.) Iberos del Ebro. Actas II Congreso Internacional (Alcañiz-Tivissa, 16-19 de noviembre de 2011), Documenta, 25: 305-320.

Melguizo Aísa, S. (2005): Íberos en el Bajo Regallo, Caspe.

Moneo, T. (2003): Religio Iberica. Santuarios, ritos y divinidades (siglos VII-I A.C.). Bibliotheca Archaeologica Hispana, 20. Real Academia de la Historia, Madrid.

Nolla, J.M.; Palahí, LL.; Vivo, J. (2010): De l'oppidum a la civitas. La romanització inicial de la Indigècia. Institut de Recerca Històrica de la Universitat de Girona, Girona.

Ñaco Del Hoyo, T.; Principal, J. (2012): Outposts of integration? Garrisoning, Logistics and Archaeology in N.E. Hispania, 133-82 BCE, S. ROSELAAR (ed.), Integration and Identity in the Roman Republic.

Oliver Foix, A. (1994): Aproximación a la problemática de las estelas epigráficas funerarias ibéricas no decoradas, V Congreso Internacional de Estelas Funerarias, Vol. 1 (Soria, 1993), Soria: 107-116.

Oliver Foix, A. (1996): Las estelas monolíticas ibéricas. Una aproximación a su problemática, Espacio, Tiempo y Forma, Serie I, Prehistoria y Arqueología, 9: 225-238.

Padrós, C. (2010): Els camins antics i les vies romanes a la comarca d’Osona (Barcelona). Estat de la qüestió, Quaderns de Prehistòria i Arqueologia de Castelló, 28: 233-245.

Pina Polo, F. (2003): ¿Por qué fue reclutada la turma Salluitana en Salduie?, Gerión, 21/1: 197-204.

Quesada Sanz, F. (1994): Lanzas hincadas, Aristóteles y las estelas del Bajo Aragón, V Congreso Internacional de Estelas Funerarias, Vol. 1 (Soria, 1993), Soria: 107-116.

Quesada Sanz, F. (2000): Territorio, etnicidad y cultura material. Estelas “Del Bajo Aragón”... en Cataluña Nororiental, Kalathos, 18-19: 95-106.

Quesada Sanz, F. (2002): La evolución de la panoplia. Modelos de combate y tácticas de los iberos, La guerra en el mundo ibérico y celtibérico (ss. VI-II a. de C.), Collection de la Casa de Velázquez (78): 35-64.

Roldán Hervás, J. M. (1974): Hispania y el ejército romano. Contribución a la historia social de la España Antigua. Salamanca.

Sanmartí Grego, E. (1988): Una estela de guerrer procedent d’Empúries, Fonaments, 7: 111-114.

Schulten, A. (1912): Les pointes de lances représentées sur les stèles funéraires, Bulletin Hispanique, $14: 196$.

Vilaplana, J. (1953): Estela ibérica ausetana, Ausa, 1: 101-103.

Zamora, D.; Pujol, J.; Garcia, J; Cela, X. (2001): El poblament a la Laietània central i Septentrional durant el període Ibèric Ple. Una proposta d'organització territorial, Martín, A. y Plana, R. (coords.) Territori polític i territori rural durant l'edat del Ferro a la Mediterrània occidental: actes de la taula rodona celebrada a Ullastret del 25 al 27 de maig de 2000: 203-226.

Recibido: 06/10/11

Aceptado: 21/06/13 